\title{
NANOSECOND Yb FIBRE LASER MILLING OF ALUMINIUM BRONZE: EFFECT OF PROCESS PARAMETERS ON THE SURFACE FINISH
}

\author{
Peter Šugár1', Jana Šugárová', Martin Frnčík', Barbora Ludrovcová1 \\ 1 Slovak University of Technology, Faculty of Materials Science and Technology, Institute of Production \\ Technologies, J. Bottu 25, 91724 Trnava, Slovakia, e-mail: peter.sugar@stuba.sk
}

Received: 2017.10.22

Accepted: 2018.07.19

Published: 2018.09.01

\begin{abstract}
In this study the relationship between laser beam machining parameters and machined surface quality, applying nanosecond pulsed ytterbium fibre laser (wavelenght 1064 $\mathrm{nm}$, maximal average output power $100 \mathrm{~W}$ ) and aluminium bronze (AMPCO $25^{\circledR}$ ) as working material, is experimentally studied. The laser micromilling was performed via the cross hatching milling strategy. The influence of the laser pulse intensity, scanning speed and laser track distance on the machined surface morphology formation and surface roughness parameters was evaluated using ANOVA (Analysis of Variance). Finally, the machining quality was evaluated by means of SEM micrographs. The results show that the laser pulse intensity played the most significant role on the final surface morphology formation. It was also documented only negligible influence of the laser track distance on the final surface roughness.
\end{abstract}

Keywords: laser milling, aluminium bronze, surface roughness.

\section{INTRODUCTION}

Laser beam milling is one of the most widely used advanced machining processes that removes material by ablation in a layer-by-layer fashion. One of the most important considerations of the laser beam milling is complex quality of the machined surface, which generally includes surface roughness, residual stresses, micro-hardness, white layer formation, microstructure transformation and so on. Different surface quality and functional performance of machined product can be obtained mainly by varying laser pulses parameters and laser machining strategy, which together with a type of workpiece material determine whether evaporation, melt ejection or vaporization dominates the process of material removal and machined surface morphology formation [1]. Optimal selection of process parameters is highly critical for successful material removal and high machined surface quality.
There are many studies which deal with how laser machining parameters affect the removal rate and the quality of machined surface of different types of materials $[2 \div 8]$. Regarding the laser machining of copper the research work of Tunna et al. [9] should be mentioned. They investigated physical effects of processing $99.9 \%$ copper at three wavelengths and a range of intensities. They stated that maximum removal rate per pulse when processing at $1064 \mathrm{~nm}$ was considerably less than the maximum removal rates observed when processing with 355 and $532 \mathrm{~nm}$. The range of thermal vaporization dominated machining of copper using Nd:YAG nanosecond laser was studied and the optimum laser intensities for micromachining was suggested in [10]. It was documented that the most efficient material removal is achieved by irradiating pulses in the optimum fluence range. Research works $[11,12]$ have shown that during micromachining of copper, both material removal rate and machined surface quality increase by using femtosecond compared to picosecond laser pulses. Fem- 
tosecond laser ablation of copper, by experimental and numerical way, is studied in [13].

From the review of actual research works it is found that many studies deal with the problem of laser processing of pure copper, but less effort was devoted to the study of laser micromachining of different types of copper-based alloys $[14,15]$. These studies also provide insight into optimizing process parameters to improve mainly the material removal mechanisms, a little less attention is given to the machined surfaces quality. In order to gain deeper insight in this research topic, laser micromachining of aluminium bronze is studied in this article. The influence of nanosecond laser processing on the machined surface morphology and surface roughness is experimentally evaluated.

\section{METHODS AND MATERIALS}

In order to contribute to understanding the relationships between process parameters and surface quality of copper-based alloy (aluminium brass), the series of experiments were carried out applying the five axis highly dynamic laser preci-
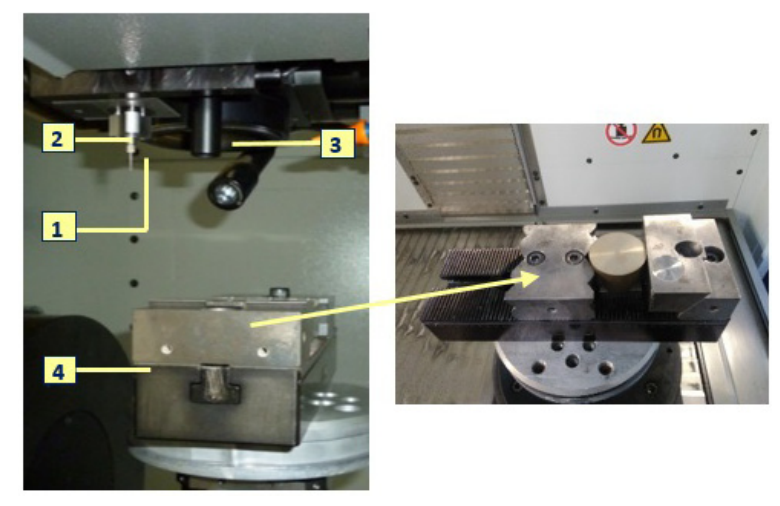

Fig. 1. Experimental set up used for laser machining 1 - beam guidance with the highly dynamic scanner acts as an optical axis system, 2 - Z-level measuring probe, 3 - positioning and measuring CCD camera, 4 - workpiece

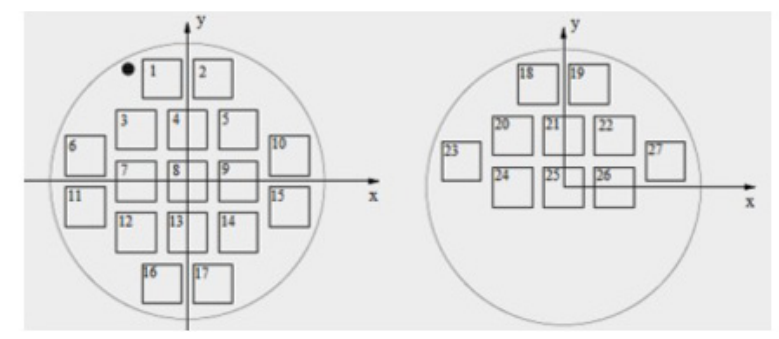

Table 1. Physical and mechanical properties of the sample [16]

\begin{tabular}{|c|c|c|c|}
\hline $\begin{array}{c}\text { Rockwell } \\
\text { hardness } \\
\text { [HR] }\end{array}$ & $\begin{array}{c}\text { Modulus of } \\
\text { elasticity } \\
{[\mathbf{G P a}]}\end{array}$ & $\begin{array}{c}\text { Density } \\
{\left[\mathbf{g} \cdot \mathbf{c m}^{-3}\right]}\end{array}$ & $\begin{array}{c}\text { Thermal } \\
\text { conductivity } \\
{\left[\mathbf{W} \cdot \mathbf{m}^{-1} \cdot \mathbf{K}^{-1}\right]}\end{array}$ \\
\hline 40 & 110 & 6.93 & 33 \\
\hline
\end{tabular}

Table 2. Factors of the experiment and their levels

\begin{tabular}{|c|c|c|c|}
\hline Experimental factor & \multicolumn{3}{|c|}{ Level } \\
\cline { 2 - 4 } & 1 & 2 & 3 \\
\hline $\begin{array}{c}\text { Laser pulse intensity (PI) } \\
{\left[\times 10^{8} \text { W.cm }{ }^{-2}\right]}\end{array}$ & 1.27 & 1.96 & 2.6 \\
\hline $\begin{array}{c}\text { Scanning speed (SS) } \\
{\left[\mathrm{mm} . \mathrm{s}^{-1}\right]}\end{array}$ & 1000 & 1600 & 2200 \\
\hline $\begin{array}{c}\text { Laser track distance (TD) } \\
{[\mu \mathrm{m}]}\end{array}$ & 12.5 & 20 & 27.5 \\
\hline
\end{tabular}

sion machining centre Lasertec 80 Shape equipped with the low-power nanosecond ytterbium-doped fiber laser (wave length $1064 \mathrm{~nm}$, maximal average output power $100 \mathrm{~W}$, pulse duration $120 \mathrm{~ns}$, repetition rate $80 \mathrm{kHz}$ ) and aluminium bronze (AMPCO $25^{\circledR}$ ) as working material. The material of workpiece is patented alloy that displays outstanding mechanical properties. The extreme hardness, linked with an excellent compressive strength and very good friction properties, makes it ideal as a forming and drawing die material. On the other hand, laser processing of this type of material has inherent problems due to its high reflectance and its very high thermal conductivity. Selected physical and mechanical properties of experimental material are shown in Table 1.

The experimental set up used for laser machining is shown in the Fig. 1.

The influence of laser pulse energy, scanning speed and laser track distance on the response surface roughness of machined surface - has been studied. The experimental layout was used in this study (three factors at three levels each). The factors and their levels are listed in Table 2.

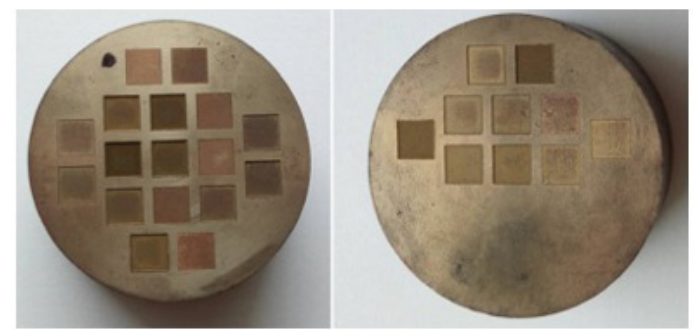

Fig. 2. Experimental sample 
Twenty seven cavities (with square shape and $5 \mathrm{~mm}$ long sides) (Fig. 2) were machined by cross hatching milling strategy, according to the full factorial plan of experiment $\left(3^{3}\right)$. The material was removed by layer-by-layer manner with total number of 30 layers.

Roughness parameters were measured using a contact-gauge profilometer Zeiss Surfcom 5000. The profile parameters $\mathrm{Ra}, \mathrm{Rq}$ and the AbbotteFirestone curve parameters Rpk, Rvk were elaborated and reported in two directions perpendicular to each other. The measurement were taken according to the standards [17, 18, 19]. Further, surface morphologies were investigated using a scanning electron microscopy (SEM) imaging. In order to quantify the effects of the studied factors and interactive influences among them on the surface profile parameters, the analysis of variance (ANOVA) using Minitab v. 17 software was performed. The Fisher's ratio (F-ratio), which is the ratio between the variance due to the effect of a factor and the variance due to an error term, was used to measure the significance of the factor at the desired significance level. If the F-test value is greater than the tabulated F-test value, the process parameter is considered significant.

\section{RESULT AND DISCUSSION}

\section{Surface roughness analysis}

The results within the scope of changes in $\mathrm{Rq}$, Rpk (this parameter is used to characterize protruding peaks that might be eliminated during function ) and Rvk (this parameter is used to characterize the valleys that will retain lubricant or worn-out materials) as a function of the laser pulse intensity applied are presented in the form of bar graphs in Fig. 3 - 5 .

It may be seen that laser machined surface finishing strongly depends on laser pulse intensities applied during the process. Worse surface finish was reached in the cases when the high values

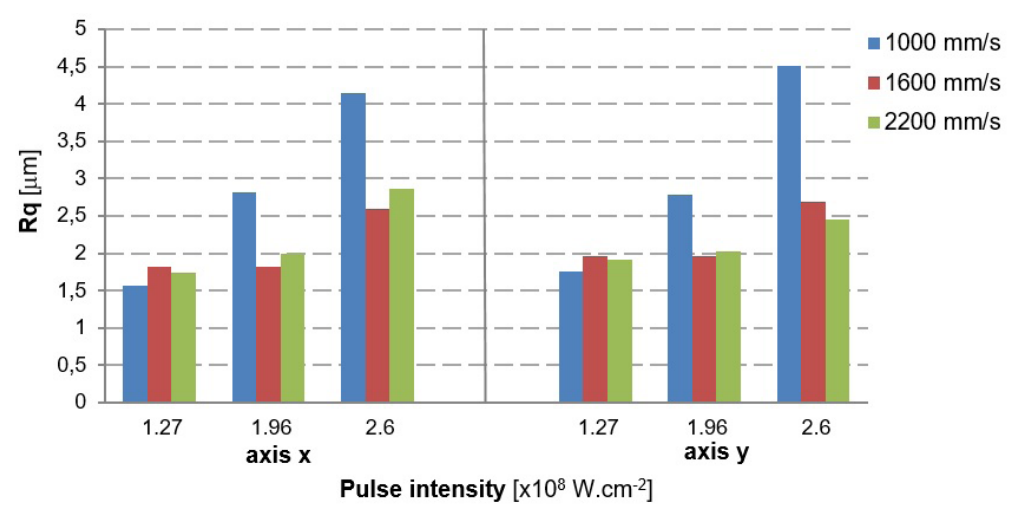

Fig. 3. Surface roughness parameter Rq of surfaces fabricated with different laser pulse intensities and scanning speeds

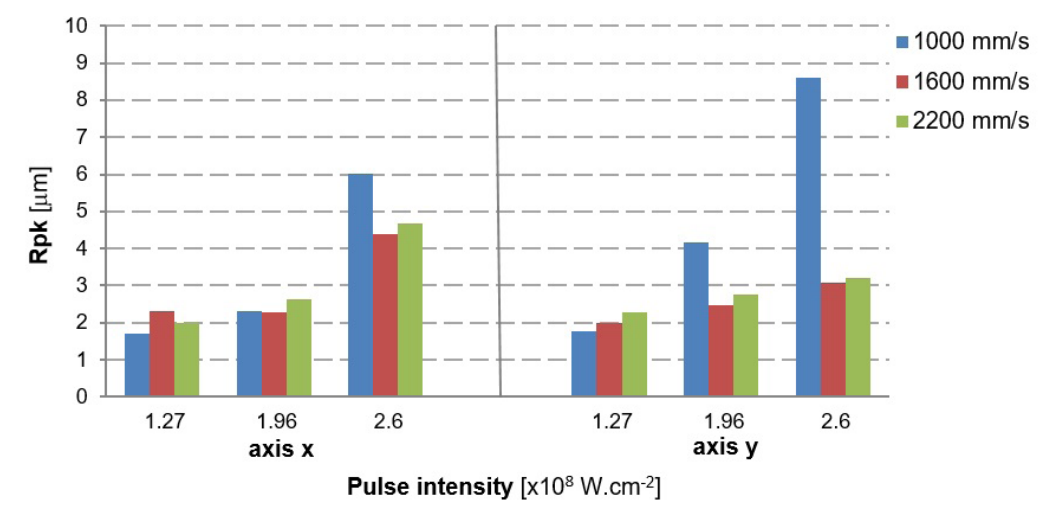

Fig. 4. Surface roughness parameter Rpk (reduced peak height) of surfaces fabricated with different laser pulse intensities and scanning speeds 


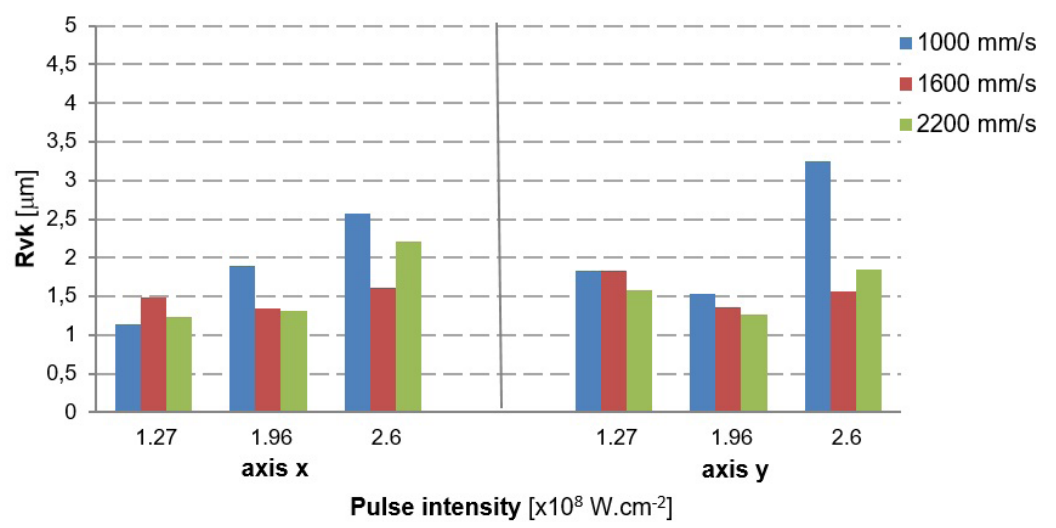

Fig. 5. Surface roughness parameter Rvk (reduced valley depth) of surfaces fabricated with different laser pulse intensities and scanning speeds

Table 3. Analysis of variance $-\mathrm{Rq}-\mathrm{x}$

\begin{tabular}{|c|c|c|c|c|c|}
\hline Source & DF & Sum of squares & Mean square & p-value & F-ratio \\
\hline Laser pulse intensity (PI) & 2 & 11.2214 & 5.6107 & 0.001 & ${ }^{* 18.29}$ \\
\hline Scanning speed (SS) & 2 & 2.0196 & 1.0098 & 0.091 & 3.29 \\
\hline Laser track distance (TD) & 2 & 0.4397 & 0.2199 & 0.517 & 0.72 \\
\hline PI * SS & 4 & 5.7039 & 1.4260 & 0.031 & 4.65 \\
\hline PI * TD & 4 & 0.9972 & 0.2493 & 0.551 & 0.81 \\
\hline SS * TD & 4 & 0.3431 & 0.0858 & 0.883 & 0.28 \\
\hline Other/Error & 8 & 2.4543 & 0.3068 & & \\
\hline Total & 26 & 23.1792 & & & \\
\hline
\end{tabular}

Tabulated F-ratio at 95\% confidence level: $\mathrm{F}(0.05 ; 2.8)=4.46 ; \mathrm{F}(0.05 ; 4.8)=3.84$

* significant parameter, $\mathrm{R}^{2}=89,41 \%, \mathrm{R}_{\text {adj }}^{2}=65,59 \%$

Table 4. Analysis of variance - Rq-y

\begin{tabular}{|c|c|c|c|c|c|}
\hline Source & DF & Sum of squares & Mean square & p-value & F-ratio \\
\hline Laser pulse intensity (PI) & 2 & 12,5633 & 6.2816 & 0.003 & ${ }^{*} 13.81$ \\
\hline Scanning speed (SS) & 2 & 3.5179 & 1.7590 & 0.067 & ${ }^{*} 3.87$ \\
\hline Laser track distance (TD) & 2 & 0.0938 & 0.0469 & 0.903 & 0.10 \\
\hline $\mathrm{PI}^{*}$ SS & 4 & 9.7838 & 2.4460 & 0.021 & 5.38 \\
\hline $\mathrm{PI}^{*}$ TD & 4 & 1.5537 & 0.3884 & 0.530 & 0.85 \\
\hline SS * TD & 4 & 1.9335 & 0.4834 & 0.434 & 1.06 \\
\hline Other/Error & 8 & 3.6381 & 0.4548 & & \\
\hline Total & 26 & 33.0842 & & & \\
\hline
\end{tabular}

Tabulated F-ratio at 95\% confidence level: $\mathrm{F}(0.05 ; 2.8)=4.46 ; \mathrm{F}(0.05 ; 4.8)=3.84$

* significant parameter, $\mathrm{R}^{2}=89 \%, \mathrm{R}_{\text {adj }}^{2}=64,26 \%$

of pulse intensity was used. The hight values of pulse intensity in combination with the minimal scanning speed give the worst microgeometrical quality of laser machined surface in both measured directions.

The results of the ANOVA and F-test for surface roughness (parameter $\mathrm{Rq}$ ) measured in the two direction, perpendicular to each other, are shown in Tables 3 and 4.

The results of ANOVA show that the significant effect of laser pulse intensity on surface finish variation is clearly seen in both measured directions. The machined surface roughness in the ydirection is also affected by scanning speed. The 


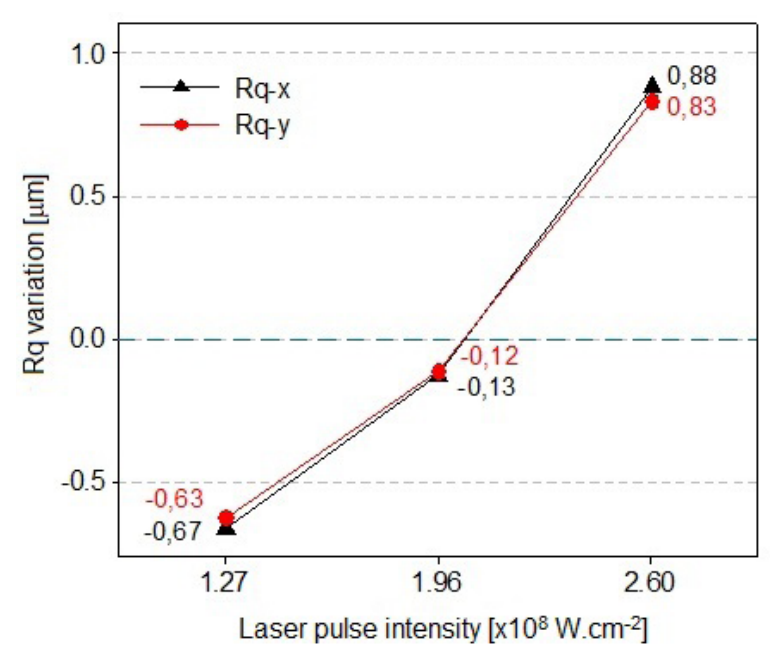

Fig. 6. Main effects plots of machined surface roughness versus laser pulse intensity

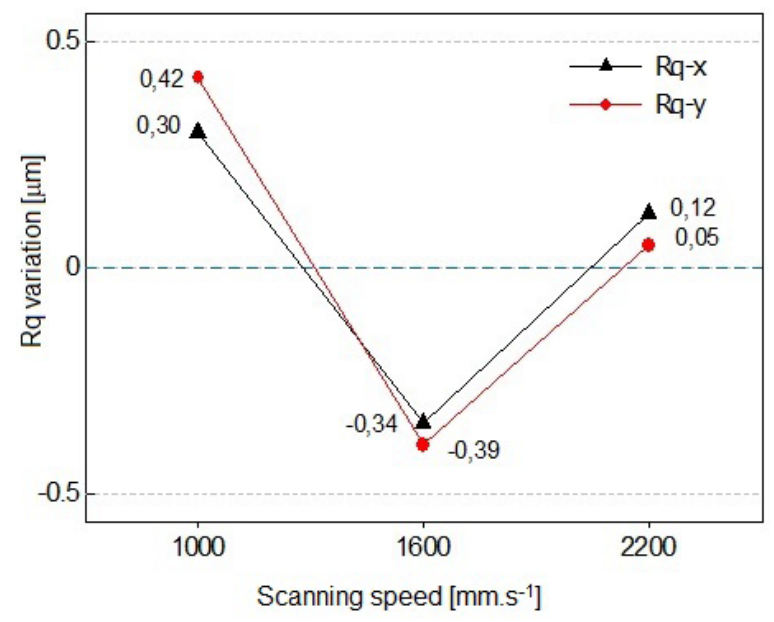

Fig. 7. Main effects plots of machined surface roughness versus scanning speed

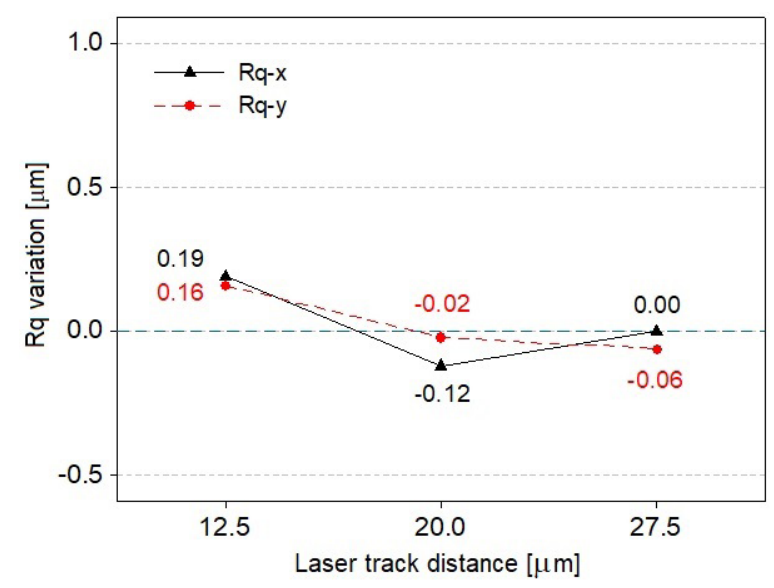

Fig. 8. Main effects plots of machined surface roughness versus laser track distance

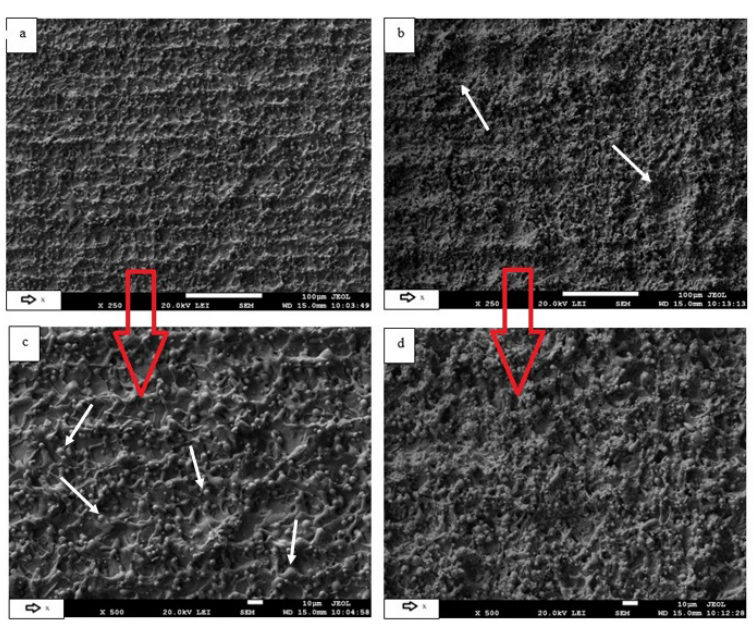

Fig. 9. SEM micrographs of machined surfaces ( $\mathrm{SS}=$ $\left.1000 \mathrm{~mm} \cdot \mathrm{s}^{-1}, \mathrm{TD}=20 \mu \mathrm{m}\right)$, a) $(250 \mathrm{x}), \mathrm{c}(500 \mathrm{x})-\mathrm{PI}$ $=1.27 \times 10^{8} \mathrm{~W} . \mathrm{cm}^{-2}$; profile parameters $\mathrm{Rq}(\mathrm{x})=1.568$ $\mu \mathrm{m}, \mathrm{Rq}(\mathrm{y})=1.761 \mu \mathrm{m}, \mathrm{b})(250 \mathrm{x}), \mathrm{d}(500 \mathrm{x})-\mathrm{PI}=2.6$ $\mathrm{x} 10^{8} \mathrm{~W} . \mathrm{cm}^{-2}$; profile parameters $\mathrm{Rq}(\mathrm{x})=4.149 \mu \mathrm{m}$,

$$
\mathrm{Rq}(\mathrm{y})=4.517 \mu \mathrm{m}
$$

results further showed that for surface roughness there is only one significant interaction among the input parameters, which is the laser pulse intensity and scanning speed (F-ratio: 4.65 to 5.38 ).

Fig. $6-8$ show graphs of the effects of the input parameters on the surface roughness. It is clear that maximal roughness can be expected when the maximal high pulse intensity in combination with low scanning speed is used.

The SEM microghaphs of selected machined surfaces in Fig. 9 show transition in surface morphology when different laser pulse intensities are applied. The machined surfaces are created by molten and resolified particles of micrometer scale, which are more evident in the case when the lower pulse intensity is used (a few of them are highlighted by white arrows in Fig. 9c). Laser irradiation of lower pulse intensity resulted in creating directionaly oriented texture (Fig. 9a). Despite the fact that micro melt structure of surfaces produced under higher pulse intensity (Fig. 9b, d) seem to be finer, an unintended microcraters of diameter approximately $30-40 \mu \mathrm{m}$, randomly originated at the surface (highligted by white arrow in Fig. 9b), cause the downgrade of the surface quality.

\section{CONCLUSIONS}

On the basis of the results obtained from this investigation and statistical analysis, the following conclusions can be drawn: 
- Significant effect of the laser pulse intensity on the surface morphology and surface roughness has been observed that is in adition affected by scanning speed. It was confirmed that high laser pulse intensities lead to the worst surface finish. It agrees with the results of other authors, who studied the laser machining parameters influence on machined surface quality for copper $[9,11,12]$ and reported that only a very narrow range $(1.06 \mathrm{x}$ $10^{8}$ to $1.8 \times 10^{8} \mathrm{~W} . \mathrm{cm}^{-2}$ ) of vaporisation dominated ablation exists for nanosecond lasers. At high intensities plasma effects and gas dynamic effects and their impact on the surface quality should be considered [10].

- Only minimal effect has been reported in the case of laser track distance.

- For the best results the laser pulse intensity 1.27 $\mathrm{x} 10^{8} \mathrm{~W} \cdot \mathrm{cm}^{-2}$ is recommended in combination with scanning speed $1600 \mathrm{~mm} \cdot \mathrm{s}^{-1}$ and laser track distance $20 \mu \mathrm{m}$, which means $60 \%$ transverse overlap of consecutive laser beam tracks.

\section{ACKNOWLEDGMENTS}

This research was supported by an international research project under the MANUNET 2014 call, entitled: Innovative methods of sheet metal forming tools surfaces improvement - R\&D (2014/11283); and VEGA project: Laser surface texturing technology research for an optimizing of tribology conditions in the sheet metal forming processes $(1 / 0669 / 15)$ and the authors would also like to thank for financial contribution from the STU Grand Scheme for Support of Young Researchers (project SURFTOOL 1386). The authors also express their sincere thanks to Dr. Ingrid Görögová for her assistance with surface roughness evaluation and dr. Martin Sahul and dr. Miroslav Sahul for their assistance with SEM analysis.

\section{REFERENCES}

1. Mishra S. and Yadava V. Laser Beam MicroMachining (LBMM) - A review. Optics \& Laser Technology 73 (2015), $89-122$.

2. Kong M. C. and Wang J. Surface Quality Analysis of Titanium and Nickel-based Alloys Using Picosecond Laser. Procedia CIRP 13 ( 2014 ), 417 - 422.

3. Ciruana J., Arias G. and Ozel T. Neural Network Modeling and Particle Swarm Optimization (PSO) of Process Parameters in Pulsed Laser Micromachining of Hardened AISI H13 Steel. Materials and Manufacturing Processes, 24, no. 3 (2009), 358-368.
4. Campanelli S. L. et al. Experimental analysis of the laser milling process parameters. Journal of Materials Processing Technology, 191, no. 1-3, (2007), 220-223.

5. Semaltianos N. G. et al. Picosecond laser ablation of nickel-based superalloy C263. Applied Physics A: Materials Science and Processing, 98, no. 2, (2010), 345-355.

6. Kaldos A. Laser machining in die making - a modern rapid tooling proces. Journal of Materials Processing Technology, 155-156, 1815-1820.

7. Cicala E. et al. The application of the random balance method in laser machining of metals. Journal of Materials Processing Technology, 196, (1-3), 393-401.

8. Cheng J. Effects of laser operating parameters on metals micromachining with ultrafast lasers. Applied Surface Science 256, no. 5 (2009), 1514-1520.

9. Tunna L. et al. Micromachining of copper using $\mathrm{Nd}$ :YAG laser radiation at 1064,532 , and 355 $\mathrm{nm}$ wavelengths. Optics \& Laser Technology 33 (2001), $135-143$.

10. Zhang W., Yao Y. L. and Chen K. Modelling and Analysis of UV Laser Micromachining of Copper. International Journal of Advanced Manufacturing Techology 18 (2001), 323 - 331.

11. Schielle J., Schneider L. and Loeschner U. Process optimization in high-average-power ultrashort pulse laser microfabrication: how laser process parameters influence efficiency, throughput and quality. Applied Physics A - Materials Science \& Processing, 120(3), 2015, $847-855$.

12. Schielle J. et al. High-pulse repetition frequency ultrashort pulse laser processing of copper. Journal of laser applications. 27(S2), 2015, S28007-1 - S28007-6.

13. Wang S. Y. et al. Micromachining of copper by femtosecond laser pulses. Applied Surface Science 265 (2013), $302-308$.

14. Gattani V. et al. Laser Surface Texturing of Aluminium Silicon and Aluminium Bronze to Enhance Tribological Properties. International Journal of Engineering Research \& Technology, 4(12), 2015, 619-624.

15. Maisterrena-Epstein, R. et al. Nanosecond laser ablation of bulk $\mathrm{Al}$, Bronze, and $\mathrm{Cu}$ : ablation rate saturation and laser-induced oxidation. Superficies y Vacío. 20(3), 2007, 1-5.

16. Ampco Metal, 2017. [online] Aviable at: <https:// www.ampcometal.com $>$ [Accessed 1st June 2017].

17. ISO 25178-2:2012 Geometrical product specifications (GPS) - Surface texture: Areal - Part 2: Terms, definitions and surface texture parameters.

18. ISO 25178-3:2012 Geometrical product specifications (GPS) - Surface texture: Areal - Part 3: Specification operators.

19. ISO 25178-601:2010 Geometrical product specifications (GPS) - Surface texture: Areal - Part 601: Nominal characteristics of contact (stylus) instruments. 